\title{
Accuracy of Oxygen Consumption and Carbon Dioxide Elimination Measurements in 2 Breath-by-Breath Devices
}

\author{
Craig D Smallwood RRT, John N Kheir MD, Brian K Walsh PhD RRT-NPS FAARC, and \\ Nilesh M Mehta MD
}

\begin{abstract}
BACKGROUND: Although accurate quantification of oxygen consumption $\left(\dot{\mathrm{V}}_{\mathrm{O}_{2}}\right)$ and carbon dioxide elimination $\left(\dot{\mathrm{V}}_{\mathrm{CO}_{2}}\right.$ ) provides important insights into a patient's nutritional and hemodynamic status, few devices exist to accurately measure these parameters in children. Therefore, we assessed the accuracy and agreement of $\mathbf{2}$ devices currently on the market using a pediatric in vitro model of gas exchange. METHODS: We utilized a Huszczuk simulation model, which simulates oxygen consumption and carbon dioxide production using gas dilution, to examine the accuracy of two FDA-cleared respiratory modules (E-COVX and E-sCAiOVX-00). $\dot{\mathrm{V}}_{\mathrm{O}_{2}}$ and $\dot{\mathrm{V}}_{\mathrm{CO}_{2}}$ were set at 20, 40,60 , and $100 \mathrm{~mL} / \mathrm{min}$, ranges typical for infant and pediatric patients. Bland-Altman analysis was used to calculate the bias and limits of agreement of each device relative to simulated values for $\dot{\mathrm{V}}_{\mathrm{O}_{2}}$ and $\dot{\mathrm{V}}_{\mathrm{CO}_{2}}$. RESULTS: The E-COVX mean percentage bias (limits of agreement) was $-26.3 \%(-36.1$ to $-16.6 \%)$ and $-39.3 \%(-47.5$ to $-31.1 \%)$ for $\dot{\mathrm{V}}_{\mathrm{O}_{2}}$ and $\dot{\mathrm{V}}_{\mathrm{CO}_{2}}$, respectively. The mean bias (limits of agreement) for the E-aCAiOVX-00 was $-0.5 \%(-13.3$ to $12.3 \%)$ and $-6.0 \%(-13.8$ to $1.7 \%)$ for $\dot{\mathrm{V}}_{\mathrm{O}_{2}}$ and $\dot{\mathrm{V}}_{\mathrm{CO}}$, respectively. CONCLUSIONS: The E-COVX demonstrated bias and limits of agreement that were not clinically acceptable; therefore, application of this module to pediatric patients would not be recommended. The new module, E-sCAiOVX, demonstrated acceptable bias and limits of agreement for the $\dot{\mathrm{V}}_{\mathrm{O}_{2}}$ and $\dot{\mathbf{V}}_{\mathrm{CO}_{2}}$ in the range $40-100 \mathrm{~mL} / \mathrm{min}$ (which corresponds to patients in the range of $\sim 5-16 \mathrm{~kg}$ ). Key words: gas exchange; carbon dioxide elimination; oxygen consumption; indirect calorimetry; accuracy. [Respir Care 2017;62(4):475-480. (C) 2017 Daedalus Enterprises]
\end{abstract}

\section{Introduction}

The accurate quantification of oxygen consumption $\left(\dot{\mathrm{V}}_{\mathrm{O}_{2}}\right)$ and carbon dioxide elimination $\left(\dot{\mathrm{V}}_{\mathrm{CO}_{2}}\right)$ in critically ill, mechanically ventilated children is central to the assessment of nutritional status and hemodynamics. ${ }^{1-3}$ However, an accurate and broadly useful tool to quantify $\dot{\mathrm{V}}_{\mathrm{O}_{2}}$, in particular, has remained elusive. Most devices available on

\footnotetext{
Mr Smallwood, Dr Walsh, and Dr Mehta are affiliated with the Division of Critical Care Medicine, Department of Anesthesiology, Perioperative and Pain Medicine, and Dr Kheir is affiliated with the Department of Cardiology, Boston Children's Hospital, Boston, Massachusetts. Mr Smallwood, Dr Walsh, and Dr Mehta are affiliated with Harvard Medical School, Boston, Massachusetts.
}

The authors have disclosed no conflicts of interest. the market are not specifically designed to measure gas exchange in children, and accuracy data are rarely reported. ${ }^{4}$ Gas exchange parameters are essential for understanding energy requirements in critically ill patients and in estimating cardiac output using the Fick equation and $\mathrm{CO}_{2}$ rebreathing. ${ }^{1,5-7}$ Recently, alternative methods for estimating energy expenditure have arisen that attempt to obviate the need to accurately measure $\dot{\mathrm{V}}_{\mathrm{O}_{2}}$ by measuring

\footnotetext{
Correspondence: Craig D Smallwood RRT, Division of Critical Care Medicine, Department of Anesthesiology, Pain and Perioperative Medicine, MSICU Office, Bader 634, Boston Children's Hospital, 300 Longwood Avenue, Boston, MA 02115. E-mail: craig.smallwood@childrens.harvard.edu.
}

DOI: $10.4187 /$ respcare. 05115 
$\dot{\mathrm{V}}_{\mathrm{CO}_{2}}$ and utilizing a consistent assumed respiratory quotient. ${ }^{8,9}$ Further, due to the challenges of accurately quantifying $\dot{\mathrm{V}}_{\mathrm{O}_{2}}$, many pediatric institutions estimate (rather than measure) this vital parameter based on healthy controls, but this practice is known to cause significant errors in cardiac output estimates. ${ }^{10,11}$

Although investigations have been conducted on previous generations of devices, recent improvements may affect the accuracy of measurements. ${ }^{12,13}$ We therefore sought to compare the accuracy of these 2 modules within the range of expected $\dot{\mathrm{V}}_{\mathrm{O}_{2}}$ and $\dot{\mathrm{V}}_{\mathrm{CO}_{2}}$ values for pediatric patients using an experimental model of simulated respiration.

\section{Methods}

\section{Gas Exchange Simulation}

As described previously, ${ }^{14,15}$ we constructed a benchtop simulation model that allows precise control of respiratory mechanics and gas exchange parameters. The Huszczuk method is based on mass conservation and utilizes a calibrated gas injection system to simulate $\dot{\mathrm{V}}_{\mathrm{O}_{2}}$ and $\dot{\mathrm{V}}_{\mathrm{CO}_{2}}{ }^{15}$ Briefly, a mass flow controller (FMA-2619A, Omega Engineering, Stamford, Connecticut) was utilized to control the injection of a specialized test gas composed of $21 \%$ $\mathrm{CO}_{2}$ /balance nitrogen into a customized baffle and reservoir assembly; the accuracy of the mass flow controller is $\pm 0.8 \%$ of the measurement reading. A precisely known volume of $21 \% \mathrm{CO}_{2}$ /balance nitrogen is pumped into the reservoir during exhalation. During inspiration, this volume of gas mixes with a measured (by the device being tested) volume of ambient air ( $21 \%$ oxygen/balance nitrogen); this dilutes the concentration of oxygen from inspired air by a known quantity, creating a precisely known lower quantity of expired oxygen than inspired oxygen, simulating oxygen consumption. Carbon dioxide elimination $\left(\dot{\mathrm{V}}_{\mathrm{CO}_{2}}\right)$ was calculated by multiplying the $\mathrm{CO}_{2}$ fraction of the test gas by the flow $(0.21 \times$ test gas flow). Since the expired oxygen concentration $\left(\mathrm{FeO}_{2}\right)$ is diluted by the addition of $\mathrm{CO}_{2}$, the simulated $\dot{\mathrm{V}}_{\mathrm{CO}_{2}}$ is equal to $\dot{\mathrm{V}}_{\mathrm{O}_{2}}$ (this relationship is only true for a test gas whose carbon dioxide concentration is precisely $0.21 /$ balance nitrogen, making this a convenient gas for this model). As an example, the calculation of the required test gas flow required to simulate $40 \mathrm{~mL} / \mathrm{min} \dot{\mathrm{V}}_{\mathrm{CO}_{2}}$ is shown below:

$$
\begin{gathered}
\dot{\mathrm{V}}_{\text {test gas }}=\dot{\mathrm{V}}_{\mathrm{CO}_{2}} \times 1 / \mathrm{FCO}_{2} \times \mathrm{k} \\
\dot{\mathrm{V}}_{\text {test gas }}=(40 \mathrm{~mL} / \mathrm{min}) \times 1 /(0.21) \times \mathrm{k} \\
\dot{\mathrm{V}}_{\text {test gas }}=190 \mathrm{~mL} / \mathrm{min} \times \mathrm{k}
\end{gathered}
$$

\section{QUICK LOOK}

\section{Current knowledge}

Increasingly, technology to measure oxygen consumption and carbon dioxide elimination is being incorporated into mechanical ventilators. These devices can offer insights into cardiopulmonary performance and nutrition status. Importantly, the technological limitations of this technology must be understood to ensure that clinical application is appropriate and accurate, especially in the pediatric range, since most devices were designed primarily for adult use.

\section{What this paper contributes to our knowledge}

Of the two devices tested, only the newest module demonstrated a bias and limits of agreement that were within an a priori determined clinically acceptable range of $\pm 20 \%$. The limits of agreement were clinically acceptable from 40 to $100 \mathrm{~mL} / \mathrm{min}$. This range corresponds to approximate patient weights of $5-16 \mathrm{~kg}$.

where $\mathrm{FCO}_{2}$ is the fraction of $\mathrm{CO}_{2}$ in the test gas and $\mathrm{k}$ is a gas density correction factor. The correction factor is only required if the mass flow controller utilized is not specifically calibrated to the test gas (in this case, the $\mathrm{k}$ term can be ignored). Therefore, the set test gas flow would be $190 \mathrm{~mL} / \mathrm{min}$ to simulate a $\dot{\mathrm{V}}_{\mathrm{CO}_{2}} / \dot{\mathrm{V}}_{\mathrm{O}_{2}}$ of $40 \mathrm{~mL} / \mathrm{min}$. In the present investigation, a correction factor, $\mathrm{k}=0.9578$ was used because the mass-flow controller was precalibrated for $\mathrm{N}_{2}$ (the test gas concentration is 0.9578 times as dense as $\mathrm{N}_{2}$ ). The QuickLung Breather (Ingmar Medical, Pittsburgh, Pennsylvania) was used to simulate tidal volumes, inspiratory times, breathing frequencies, and compliance. Compliance was set to $6 \mathrm{~mL} / \mathrm{cm} \mathrm{H}_{2} \mathrm{O}$, resistance was set to $50 \mathrm{~cm} \mathrm{H}_{2} \mathrm{O} / \mathrm{L} / \mathrm{s}$, breathing frequency was set to 20 beats/min, and $\mathrm{F}_{\mathrm{IO}_{2}}$ was set to $33 \% .{ }^{16}$

\section{Gas Exchange Monitors}

We compared the E-COVX and E-sCAiOVX-00 gas exchange modules (GE Healthcare, Helsinki, Finland) attached to a critical care monitor (Carescape B450, GE Healthcare, Helsinki, Finland). The device was calibrated according to the manufacturer's specifications. The device utilizes a fixed orifice pressure differential pneumotachometer that is preconfigured for pediatric use and does not require flow calibration. The sidestream paramagnetic $\mathrm{O}_{2}$ analyzer and near-infrared $\mathrm{CO}_{2}$ sensor were calibrated with a multipoint gas calibration. The appropriate pediatric airway adapters were used for the specified breathing frequency and tidal volumes. 
Table 1. Combination of $\dot{\mathrm{V}}_{\mathrm{O}_{2}}, \dot{\mathrm{V}}_{\mathrm{CO}_{2}}$, Inspiratory Flow, and Tidal Volumes Set on the Simulator

\begin{tabular}{lcccc}
\hline $\begin{array}{l}\text { Approximate } \\
\text { Weight }(\mathrm{kg})\end{array}$ & $\begin{array}{c}\mathrm{Set} \dot{\mathrm{V}}_{\mathrm{O}_{2}} \\
(\mathrm{~mL} / \mathrm{min})\end{array}$ & $\begin{array}{c}\text { Set } \dot{\mathrm{V}}_{\mathrm{CO}_{2}} \\
(\mathrm{~mL} / \mathrm{min})\end{array}$ & $\begin{array}{c}\text { Set } \dot{\mathrm{V}}_{\text {insp }} \\
(\mathrm{L} / \mathrm{min})\end{array}$ & $\begin{array}{c}\text { Tidal } \\
\text { Volume }(\mathrm{mL})\end{array}$ \\
\hline $5-6$ & 20 & 20 & 1.8 & 30 \\
$6-8$ & 40 & 40 & 3.0 & 50 \\
$8-10$ & 60 & 60 & 3.6 & 60 \\
$10-16$ & 100 & 100 & 5.0 & 80
\end{tabular}

These values correspond to approximate weights of $5-16 \mathrm{~kg} .{ }^{17,18}$

\section{Experimental Protocol}

To examine the accuracy of these modules within the ranges expected for infants and children, we simulated $\dot{V}_{\mathrm{O}_{2}}$ and $\dot{\mathrm{V}}_{\mathrm{CO}_{2}}$ values and tidal volumes according to Table 1 . After each combination of gas exchange and tidal volumes was selected on the simulator, an equilibration period was instituted. This ensured that measured values had reached steady state before data collection began (this period lasted $\sim 5 \mathrm{~min}$ ). For each combination, $\dot{\mathrm{V}}_{\mathrm{O}_{2}}$ and $\dot{\mathrm{V}}_{\mathrm{CO}_{2}}$ were measured for $10 \mathrm{~min}$ (no. $=20$ replicates/combination).

\section{Statistical Analysis}

We computed bias and limits of agreement for each combination shown above, comparing set $\dot{\mathrm{V}}_{\mathrm{O}_{2}}$ and $\dot{\mathrm{V}}_{\mathrm{CO}_{2}}$ (as the reference standard) with measured values of each using a Bland-Altman analysis (GraphPad Prism 5.04, GraphPad Software, La Jolla, California). We decided a priori that a $\pm 20 \%$ limit of agreement would be deemed clinically acceptable. ${ }^{19}$ For each device, we determined the minimum acceptable value that exhibited limits of agreement within the clinically acceptable range for both $\dot{\mathrm{V}}_{\mathrm{O}_{2}}$ and $\dot{\mathrm{V}}_{\mathrm{CO}_{2}}$.

\section{Results}

Differences between measured $\dot{\mathrm{V}}_{\mathrm{O}_{2}}$ and $\dot{\mathrm{V}}_{\mathrm{CO}_{2}}$ and set values for each were calculated for each experimental replicate, representing the bias of each measurement. Bias and limits of agreement for each set of conditions are depicted in Table 2, Figure 1, and Figure 2. Overall, the mean bias (95\% CI of limits of agreement) for the E-COVX across the ranges tested were $-26.3 \%(-36.1$ to $-16.6 \%$ ) for $\dot{\mathrm{V}}_{\mathrm{O}_{2}}$ and $-39.3 \%$ ( -47.5 to $-31.1 \%$ ) for $\dot{\mathrm{V}}_{\mathrm{CO}_{2}}$. The newer module, E-aCAiOVX, exhibited a mean bias of -0.5 ( -13.3 to 12.3$)$ for $\dot{\mathrm{V}}_{\mathrm{O}_{2}}$ and $-6.0(-13.8$ to 1.7) for $\dot{\mathrm{V}}_{\mathrm{CO}_{2}}$. In the E-aCAiOVX, but not the E-COVX, the limits of agreement for $\dot{\mathrm{V}}_{\mathrm{O}_{2}}$ and $\dot{\mathrm{V}}_{\mathrm{CO}_{2}}$ were within the clinically acceptable range of $\pm 20 \%$ for all set values except for $20 \mathrm{~mL} / \mathrm{min}$.
Table 2. Summary of Bias Across the Tested Range of Simulated Gas Exchange Values

\begin{tabular}{|c|c|c|c|c|}
\hline \multirow[b]{2}{*}{ Test Range } & \multicolumn{2}{|r|}{$\dot{\mathrm{V}}_{\mathrm{O}_{2}}$} & \multicolumn{2}{|r|}{$\dot{\mathrm{V}}_{\mathrm{CO}_{2}}$} \\
\hline & $\begin{array}{l}\text { Mean } \\
\text { Bias }\end{array}$ & $\begin{array}{l}95 \% \text { Limits of } \\
\text { Agreement }\end{array}$ & $\begin{array}{l}\text { Mean } \\
\text { Bias }\end{array}$ & $\begin{array}{l}95 \% \text { Limits of } \\
\text { Agreement }\end{array}$ \\
\hline \multicolumn{5}{|l|}{ E-sCAiOVX } \\
\hline $20 \mathrm{~mL} / \mathrm{min}$ & -26.8 & -38.7 to -14.9 & -12.1 & -23.8 to -0.3 \\
\hline $40 \mathrm{~mL} / \mathrm{min}$ & 5.4 & -5.5 to 16.3 & -7.4 & -17.5 to 2.6 \\
\hline $60 \mathrm{~mL} / \mathrm{min}$ & 0.6 & -5.2 to 6.4 & -2.8 & -6.7 to 1.1 \\
\hline $100 \mathrm{~mL} / \mathrm{min}$ & -7.5 & -10.9 to -4.1 & -7.8 & -10.2 to -5.5 \\
\hline \multicolumn{5}{|l|}{ E-COVX } \\
\hline $20 \mathrm{~mL} / \mathrm{min}$ & -1.6 & -13.3 to 10.0 & -48.2 & -63.4 to -32.9 \\
\hline $40 \mathrm{~mL} / \mathrm{min}$ & -21.4 & -28.2 to -14.6 & -42.6 & -48.0 to -37.3 \\
\hline $60 \mathrm{~mL} / \mathrm{min}$ & -28.2 & -35.1 to -21.2 & -38.6 & -45.8 to -31.4 \\
\hline $100 \mathrm{~mL} / \mathrm{min}$ & -29.4 & -36.6 to -22.2 & -36.6 & -43.7 to -29.5 \\
\hline
\end{tabular}

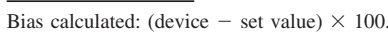

\section{Discussion}

We report the accuracy and agreement of 2 available gas exchange monitoring modules from the same manufacturer that can be used alone or incorporated into a mechanical ventilator. The results demonstrate acceptable performance (mean bias and 95\% limits of agreement) of the updated module (E-sCAiOVX) for $\dot{\mathrm{V}}_{\mathrm{O}_{2}}$ and $\dot{\mathrm{V}}_{\mathrm{CO}_{2}}$ values in the range of $40-100 \mathrm{~mL} / \mathrm{min}$ with mean inspiratory flows ranging from 3.0 to $5.0 \mathrm{~L} / \mathrm{min}$. The older device (E-COVX) did not demonstrate agreement with the simulated values and therefore is not clinically acceptable for use in pediatric patients. The findings for the E-sCAiOVX are more favorable than those described in the manufacturer's specifications. In contrast, the older device (E-COVX) exhibited significantly greater negative bias across the spectrum of ranges tested.

It should be noted that our results of the E-COVX module differed from a prior report on the M-COVX module, which reported a $<1 \%$ bias at simulated $\dot{\mathrm{V}}_{\mathrm{O}_{2}}$ as low as $50 \mathrm{~mL} / \mathrm{min} .{ }^{10}$ However, we believe that there are important differences in the way in which set $\dot{\mathrm{V}}_{\mathrm{O}_{2}}$ and $\dot{\mathrm{V}}_{\mathrm{CO}_{2}}$ and respiratory parameters were controlled that account for these differences. However, since the modules themselves do function slightly differently, it is possible that actual differences in the performance of the modules account for some of the difference.

Recently, Wines et $\mathrm{a}^{20}$ studied the accuracy of the V-max Encore metabolic cart (CareFusion, San Diego, California). The investigators utilized a commercially available gas exchange simulator (VacuMed, Ventura, California). The principle of operation is similar to that employed in the present investigation. However, the VacuMed device was designed for adult applications, and therefore 

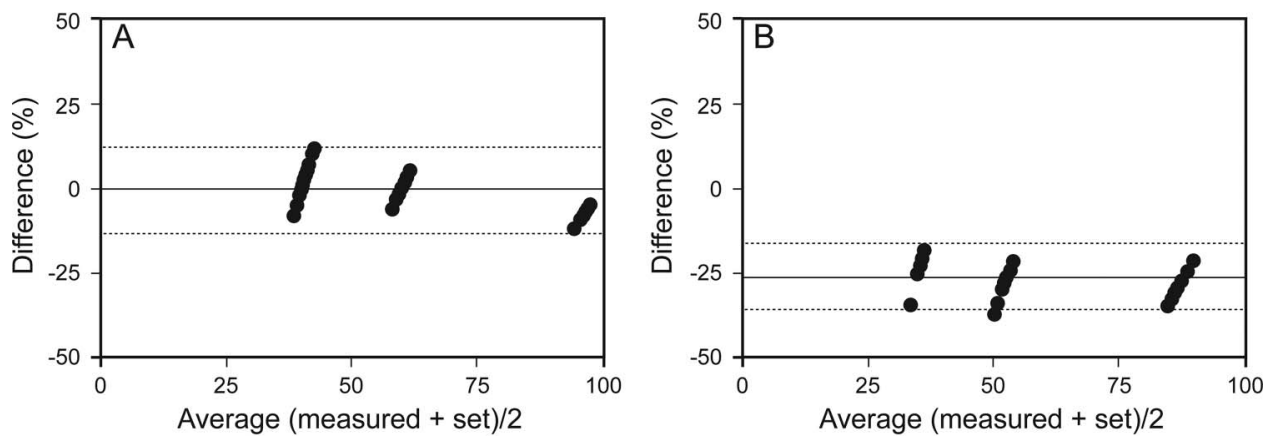

Fig. 1. Bland-Altman plots of oxygen consumption $\left(\dot{V}_{\mathrm{O}_{2}}\right)$ results as measured using the E-sCAiOVX $(A)$ and $E-C O V X(B)$ compared with the simulated values. Difference $(\%)=100 \times($ measured value - set value)/[(measured value + set value)/2] versus average of the measured value and set value. Solid lines show the mean bias, and dotted lines represent the $95 \%$ limits of agreement.
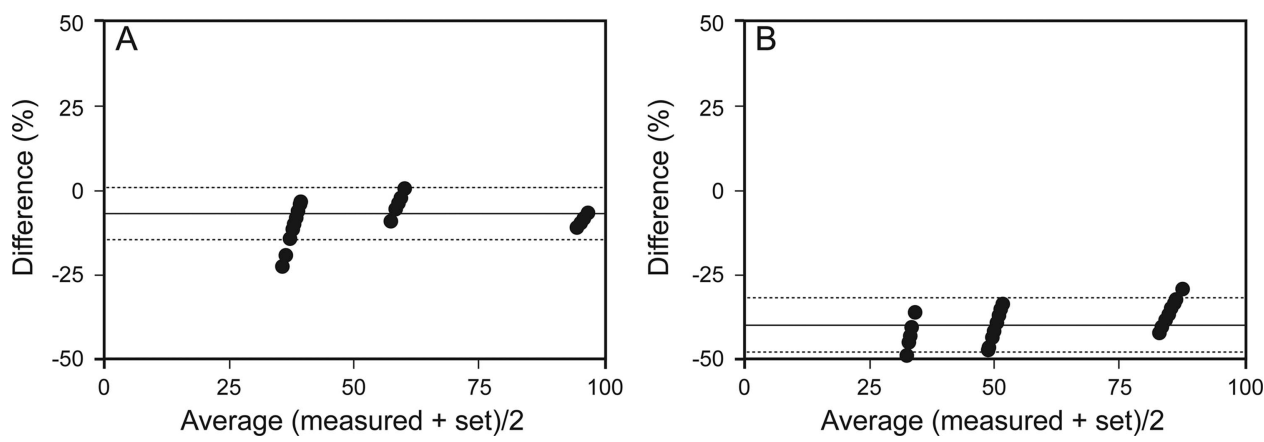

Fig. 2. Bland-Altman plots of carbon dioxide elimination $\left(\dot{V}_{\mathrm{CO}_{2}}\right)$ results as measured using the $\mathrm{E}-\mathrm{aCAiOVX}(\mathrm{A})$ and $\mathrm{E}-\mathrm{COVX}(\mathrm{B})$ compared with the simulated values. Difference $(\%)=100 \times($ measured value - set value) $/[($ measured value + set value)/2] versus average of the measured value and set value. Solid lines show the mean bias, and dotted lines represent the $95 \%$ limits of agreement.

Wines et al ${ }^{20}$ simulated pediatric $\dot{\mathrm{V}}_{\mathrm{O}_{2}}$ and $\dot{\mathrm{V}}_{\mathrm{CO}_{2}}$ levels but with tidal volumes and respiratory parameters that were much larger than would be observed in children. The authors tested gas exchange from 20 to $204 \mathrm{~mL} / \mathrm{min}$. They reported strong correlations between set and measured gas exchange values and tight limits of agreement $( \pm 7 \mathrm{~mL} / \mathrm{min})$. Unlike the present investigation, which noted reduced accuracy of the E-sCAiOVX at the $20-\mathrm{mL} / \mathrm{min}$ gas exchange range with inspiratory flow $\sim 1.8 \mathrm{~L} / \mathrm{min}$, the maximum inspiratory flow demonstrated tight limits of agreement at this range. However, since maximum inspiratory flow data were collected with adult respiratory parameters, their utility is limited, especially since the performance of flow measurement (pneumotachographs) at low inspiratory and expiratory flows is known to adversely affect the accuracy of such a system. For this reason, we sought to construct our system to ensure that pediatric respiratory parameters were incorporated.

The etiology of the performance differences between the 2 modules is not clear. Both iterations of the device utilize a paramagnetic oxygen sensor and a non-dispersive near-infrared $\mathrm{CO}_{2}$ sensor. The technical specifications outlined by the manufacturer are consistent between the two, including an accuracy of $\dot{\mathrm{V}}_{\mathrm{O}_{2}}$ and $\dot{\mathrm{V}}_{\mathrm{CO}_{2}}$ each of $\pm 10 \%$ or
$10 \mathrm{~mL}$ total (whichever is larger); we found the accuracy to be superior to this, albeit under idealized conditions as described. The only clearly visible difference is that the sampling rate in the newer device has been decreased from 200 to $120 \mathrm{~mL} / \mathrm{min}$. This decrease could reduce the entrainment of ambient gas and may decrease the dilution of inspired versus expired gas difference, improving accuracy at low $\dot{\mathrm{V}}_{\mathrm{O}_{2}}$ and $\dot{\mathrm{V}}_{\mathrm{CO}_{2}}$ measurements. It is also possible that the measurement algorithm (which matches spirometry and gas measurements to calculate $\dot{\mathrm{V}}_{\mathrm{O}_{2}}$ and $\dot{\mathrm{V}}_{\mathrm{CO}_{2}}$ ) may have improved.

The putative benefits of a commercially available device capable of measuring $\dot{\mathrm{V}}_{\mathrm{O}_{2}}$ and $\dot{\mathrm{V}}_{\mathrm{CO}_{2}}$ accurately and continuously in children cannot be overstated. In children with congenital heart disease, for example, devices may overestimate $\dot{\mathrm{V}}_{\mathrm{O}_{2}}$ (and cardiac output by a proportionate amount). This may significantly impact patient assessment, both in the cardiac catheterization laboratory and in the ICU. ${ }^{2,12,13}$ Thus, although estimates of $\dot{\mathrm{V}}_{\mathrm{O}_{2}}$ and/or $\dot{\mathrm{V}}_{\mathrm{CO}_{2}}$ for simulated values of $20 \mathrm{~mL} / \mathrm{min}$ fell outside the $20 \%$ limit of agreement, it is still possible that estimations of $\dot{\mathrm{V}}_{\mathrm{O}_{2}}$ and $\dot{\mathrm{V}}_{\mathrm{CO}_{2}}$ provided by this device would represent an improvement in the estimation of select parameters compared with standard equations. Other benefits include the titration of 


\section{Accuracy of $\dot{\mathrm{V}}_{\mathrm{O}_{2}}$ And $\dot{\mathrm{V}}_{\mathrm{CO}_{2}}$ Measurement in Pediatric Simulation}

respiratory support and accurate assessment of energy expenditure for the tailored prescription of nutrition. ${ }^{1,17,18}$ This is a subject that merits further study, although the lack of an accepted standard measure in patients makes determination of absolute accuracy difficult.

There are limitations to the present investigation. The experiment was not conducted on human subjects. Factors, including humidification, minute-to-minute variation of gas exchange values (such as occurs due to hemodynamic variability), and temperature of the circuit were not addressed. Humidification could not be incorporated into the model, since water condensate would adversely affect the performance of the mass-flow controller. Further, the effects of ventilator modes and changes in respiratory parameters are known to affect gas exchange parameters. ${ }^{21}$ We took important steps to minimize these limitations by selecting equipment that offered very good accuracy for controlling set simulated gas exchange flow, ensuring that leaks did not exist in the test apparatus and selecting combinations of pulmonary mechanics and set gas flows that corresponded to observed pediatric values. Importantly, there are advantages to conducting the investigation in a controlled laboratory environment, namely the ability to precisely control set $\dot{\mathrm{V}}_{\mathrm{O}_{2}}$ and $\dot{\mathrm{V}}_{\mathrm{CO}_{2}}$ and respiratory parameters, therefore obviating the effect that patient variability has on the interpretation of results if the experiment were to be conducted in humans. Further, since a human subject's $\dot{\mathrm{V}}_{\mathrm{O}_{2}}$ and $\dot{\mathrm{V}}_{\mathrm{CO}_{2}}$ cannot be precisely controlled, it is impossible to design a study that seeks to demonstrate the accuracy of a gas exchange monitor in vivo. This study is a comparison of the agreement between different devices. We selected a discrete range of test gas exchange values, and our conclusions are bound to this range. Further, we did not assess the affect of differences in $\mathrm{F}_{\mathrm{IO}_{2}}$ or of ventilator mode on device accuracy, either of which are known to impact these end points. ${ }^{11}$ In practice, none of these may be true, particularly in children who are weaning from the ventilator and are therefore breathing spontaneously; thus, these results must be applied to clinical practice with caution. Further investigation with methods able to incorporate increased gas exchange variability and humidification may be indicated to assess these effects on accuracy and confirm the findings of the present investigation. Nonetheless, these data provide an estimate of accuracy under idealized conditions.

\section{Conclusions}

The new module, E-sCAiOVX, demonstrated acceptable bias and limits of agreement for the $\dot{\mathrm{V}}_{\mathrm{O}_{2}}$ and $\dot{\mathrm{V}}_{\mathrm{CO}_{2}}$ in the range of $40-100 \mathrm{~mL} / \mathrm{min}$ (which corresponds to patients in the range of $\sim 6-15 \mathrm{~kg}$ ). The E-COVX demonstrated bias and limits of agreement that were not clinically acceptable, and therefore application of this module to pediatric subjects cannot be recommended in the ranges tested. Further investigations regarding the effects of patient factors, including humidity, tachypnea, and variations in inspired oxygen fractions, are warranted.

\section{REFERENCES}

1. Mehta NM, Compher C. A.S.P.E.N. clinical guidelines: nutrition support of the critically ill child. JPEN J Parenter Enteral Nutr 2009; 33(3):260-276.

2. Walsh BK, Crotwell DN, Restrepo RD. Capnography/Capnometry during mechanical ventilation: 2011. Respir Care 2011;56(4):503509 .

3. Seckeler MD, Hirsch R, Beekman RH 3rd, Goldstein BH. Validation of cardiac output using real-time measurement of oxygen consumption during cardiac catheterization in children under 3 years of age. Congenit Heart Dis 2014;9(4):307-315.

4. Mehta NM, Smallwood CD, Graham RJ. Current applications of metabolic monitoring in the pediatric intensive care unit. Nutr Clin Pract 2014;29(3):338-347.

5. Li J. Accurate measurement of oxygen consumption in children undergoing cardiac catheterization. Catheter Cardiovasc Interv 2013; 81(1):125-132.

6. Levy RJ, Chiavacci RM, Nicolson SC, Rome JJ, Lin RJ, Helfaer MA, et al. An evaluation of a noninvasive cardiac output measurement using partial carbon dioxide rebreathing in children. Anesth Analg 2004;99(6):1642-1647, table of contents.

7. Capek JM, Roy RJ. Noninvasive measurement of cardiac output using partial $\mathrm{CO}_{2}$ rebreathing. IEEE Trans Biomed Eng 1988;35(9): 653-661.

8. Mehta NM, Smallwood CD, Joosten KF, Hulst JM, Tasker RC, Duggan CP. Accuracy of a simplified equation for energy expenditure based on bedside volumetric carbon dioxide elimination measurement: a two-center study. Clin Nutr 2015;34(1):151-155.

9. Kerklaan D, Augustus ME, Hulst JM, van Rosmalen J, Verbruggen $\mathrm{SC}$, Joosten KF. Validation of ventilator-derived $\mathrm{VCO}_{2}$ measurements to determine energy expenditure in ventilated critically ill children. Clin Nutr 2016. doi: 10.1016/j.clnu.2016.01.001.

10. LaFarge CG, Miettinen OS. The estimation of oxygen consumption. Cardiovasc Res 1970;4(1):23-30.

11. Li J, Bush A, Schulze-Neick I, Penny DJ, Redington AN, Shekerdemian LS. Measured versus estimated oxygen consumption in ventilated patients with congenital heart disease: the validity of predictive equations. Crit Care Med 2003;31(4):1235-1240.

12. Stuart-Andrews CR, Peyton P, Robinson GJ, Terry D, O'Connor B, Van der Herten C, Lithgow B. In vivo validation of the M-COVX metabolic monitor in patients under anaesthesia. Anaesth Intensive Care 2007;35(3):398-405.

13. Stuart-Andrews CR, Peyton P, Walker TB, Cairncross AD, Robinson GJ, Lithgow B. Laboratory validation of the M-COVX metabolic module in measurement of oxygen uptake. Anaesth Intensive Care 2009;37(3):399-406.

14. Smallwood CD, Martinez EE, Mehta NM. A comparison of carbon dioxide elimination measurements between a portable indirect calorimeter and volumetric capnography monitor: an in vitro simulation. Respir Care 2016;61(3):354-358.

15. Huszczuk A, Whipp BJ, Wasserman K. A respiratory gas exchange simulator for routine calibration in metabolic studies. Eur Respir J 1990;3(4):465-468.

16. Gerhardt T, Hehre D, Feller R, Reifenberg L, Bancalari E. Pulmonary mechanics in normal infants and young children during first 5 years of life. Pediatr Pulmonol 1987;3(5):309-316. 


\section{Accuracy of $\dot{\mathrm{V}}_{\mathrm{O}_{2}}$ And $\dot{\mathrm{V}}_{\mathrm{CO}_{2}}$ Measurement in Pediatric Simulation}

17. White MS, Shepherd RW, McEniery JA. Energy expenditure in 100 ventilated, critically ill children: improving the accuracy of predictive equations. Crit Care Med 2000;28(7):2307-2312.

18. Mehta NM, Bechard LJ, Dolan M, Ariagno K, Jiang H, Duggan C. Energy imbalance and the risk of overfeeding in critically ill children. Pediatr Crit Care Med 2011;12(4):398-405.

19. Behrends M, Kernbach M, Bräuer A, Braun U, Peters J, Weyland W. In vitro validation of a metabolic monitor for gas exchange mea- surements in ventilated neonates. Intensive Care Med 2001;27(1): 228-235.

20. Wines KN, Rzepecki AK, Andrews AL, Dechert RE. Validation of the $\mathrm{V}_{\max }$ metabolic cart in a simulated pediatric model. JPEN $\mathrm{J}$ Parenter Enteral Nutr 2015;39(3):353-358.

21. Brandi LS, Bertolini R, Santini L, Cavani S. Effects of ventilator resetting on indirect calorimetry measurement in the critically ill surgical patient. Crit Care Med 1999;27(3):531-539. 